\title{
Does the lack of root hairs alter root system architecture of Zea mays?
}

\author{
Eva Lippold (D) Maxime Phalempin (D). \\ Steffen Schlüter $(\mathbb{D} \cdot$ Doris Vetterlein
}

Received: 23 November 2020 / Accepted: 8 July 2021 / Published online: 29 July 2021

(C) The Author(s) 2021

\begin{abstract}
Aims Root hairs are one root trait among many which enables plants to adapt to environmental conditions. How different traits are coordinated and whether some are mutually exclusive is currently poorly understood. Comparing a root hair defective mutant with its corresponding wild-type, we explored if and how the mutant exhibited root growth adaptation strategies and how dependent this was on substrate.

Methods Zea mays root hair defective mutant (rth3) and the corresponding wild-type siblings were grown under well-watered conditions on two substrates with contrasting texture and hence nutrient mobility. Root system architecture was investigated over time using repeated X-ray computed tomography.
\end{abstract}

Responsible Editor: Tim S. George.

Supplementary Information The online version contains supplementary material available at https://doi. org/10.1007/s11104-021-05084-8.

E. Lippold $(\bowtie) \cdot$ M. Phalempin $\cdot$ S. Schlüter ·

D. Vetterlein

Department of Soil System Science, Helmholtz

Centre for Environmental Research - UFZ,

Theodor-Lieser-Strasse. 4, 06120 Halle/Saale, Germany

e-mail: eva.lippold@ufz.de

D. Vetterlein

Soil Sciences, Martin Luther University Halle-Wittenberg, Von-Seckendorff-Platz 3, 06120 Halle/Saale, Germany
Results There was no plastic adaptation of root system architecture to the lack of root hairs, which resulted in lower uptake of nutrients especially in the substrate with high sorption capacity. The function of the root hairs for anchoring did not result in different root length density profiles between genotypes. Both maize genotypes showed a marked response to substrate. This was well reflected in the spatiotemporal development of rhizosphere volume fraction but especially in the highly significant response of root diameter to substrate, irrespective of genotype.

Conclusions The most salient root plasticity trait was root diameter in response to substrate. Coping mechanisms for missing root hairs were limited to a shift in root-shoot ratio in loam. Further experiments are required, to elucidate whether observed differences can be explained by mechanical properties beyond mechanical impedance, root or microbiome ethylene production or differences in diffusion processes within the root or the rhizosphere.

Keywords Nutrient availability · Plasticity · Rhizosphere $\cdot$ Root hairs $\cdot$ Texture $\cdot$ Zea mays
Abbreviations
CT Computed tomography
DAP Days after planting
L Loam
RDH Root distance histogram
RLD Root length density
rth3 Root hair defective mutant 
RVF Root volume fraction

S Sand

WT Wild-type

\section{Introduction}

Root hairs are important for nutrient uptake, in particular for those with low mobility like phosphorus (P) (Bates and Lynch 2001; Jungk 2001). In addition, root hairs are thought to be important for anchorage during establishment and root tip penetration into the soil (Bengough et al. 2016; Haling et al. 2013). Their role for water uptake is discussed controversially (Carminati et al. 2017; Marin et al. 2020). Root hair formation as an anatomical feature is just one root trait among many which enables plants to adapt to environmental conditions such as low nutrient availability, limited water supply or unfavourable physical conditions (Schmidt and Gaudin 2017). Other plastic root morphological traits include changes in root diameter (diameter distribution, specific root length) or an overall change in root distribution in space. In summary, alterations in root system architecture enable an extremely flexible response to soil physical factors and limited or heterogeneous distribution of resources in time and space (Hodge 2009; Morris et al. 2017). Furthermore, physiological traits can be altered, like activities of nutrient transporters and water channels, release of specific root exudates, and investment in mycorrhizal symbioses (Hodge 2006; Pierret et al. 2007; Schmidt and Gaudin 2017; Wen et al. 2019). Such alterations would be reflected in higher normalized uptake rates (Schmidt and Gaudin 2017). As all these root traits come at different carbon costs for establishment and maintenance, the extent to which they are exploited is potentially reflected in the root:shoot ratio (Klamer et al. 2019; Lynch and Ho 2005). How the different traits are coordinated and whether some are mutually exclusive is currently poorly understood (Wen et al. 2019). The relative importance of root traits is probably modulated by the soil and its physical and chemical properties. On the one hand nutrient availability depends on the sorption capacity and the forms of binding for the nutrients in question, for instance Phosphorus (P) (Wang and Lambers 2020). On the other hand texture related properties such as mechanical impedance, macroporosity, water holding capacity and aeration strongly impact root system architecture (Bengough et al. 2011; Lucas et al. 2019) and specifically root hair length (Hoffmann and Jungk 1995). Hairs favour contact in low strength soils, and improve penetration of high strength soils, hence their relevance for $\mathrm{P}$ uptake is expected to depend on soil physical conditions (Haling et al. 2013).

To address the plasticity of root traits in response to the lack of hairs under different soil physical conditions we compared a root hair defective mutant to the corresponding wild-type in two substrates. Specifically, we investigated the following hypotheses:

(1) Under nutrient limited conditions, the lack of root hairs will be compensated by an increased investment in root growth in general and more specifically in the growth of fine roots to maintain sufficient root surface area;

(2) The role of root hairs for anchorage will cause an adaptation in root system architecture, more specifically soil depth exploration with time, which could partly mask their expected response to low nutrient availability;

(3) The differences between wild-type and mutant will be larger in a substrate with a high sorption capacity, i.e. low mobility of the limiting nutrients, as this increases the need for enhanced soil exploration;

(4) Substrate itself will alter root system architecture, irrespective of genotype and nutrient supply, due to differences in mechanical properties and aeration.

In this study Zea mays root hair defective mutant (rth3) and the corresponding wild-type siblings (WT) were grown for three weeks under well-watered conditions on two substrates with contrasting texture and hence nutrient mobility; loam and sand. Root system architecture was investigated non-invasively by repeated X-ray computed tomography $(\mathrm{CT})$ over time. This enabled not only to derive spatial distribution of roots over time, but likewise to address the changes in root demography and hence the spatial distribution of 'active' roots. The latter is important, since we assumed that roots and in particular root hairs are only functional in uptake for a few days (Jungk 2001; Vetterlein and Doussan 2016). The potential and limitations of X-ray CT as a non-invasive tool to study root system architecture in 4D is explored in detail. From this data we were able to observe changes over 
time and to derive rhizosphere volume fractions (RVF); traits that cannot be achieved by destructive sampling. We also used conventional destructive root sampling to provide independent validations for root lengths and root diameters.

\section{Materials and methods}

Experimental design

The main experiment was set up as a two factorial, randomised design with six replicates. The term replicates here refers to individual soil columns. Factor one was substrate with two levels (loam (L), sand (S)). Factor two was Zea mays genotype with two levels comprising B73 wild-type (WT), and a root hair defective mutant (rth3). The experiment was set up in duplicate; one set consisting of six columns for each of the four treatments (L_WT, L_rth3, S_WT, S_rth3) was used for X-ray CT scanning. The other set, likewise with six columns per treatment, served as a control to check whether the X-ray dose associated with CT scanning had an impact on the parameters of interest (Control). The results presented refer to the six scanned replicates per treatment. For shoot dry weight and root length, the comparison between scanned columns and control is shown in the supplement.

\section{Genotypes}

For the experiments, the Zea mays root hair defective mutant $r$ th 3 and the corresponding wild-type siblings were selected (Wen and Schnable 1994).

The monogenic mutant $r$ th 3 is transposon induced and shows normal root hair initiation but disturbed elongation. The mutant shows no apparent aberrant shoot phenotype, but grain yield in field experiments is reduced by 19 to $42 \%$ compared to the wild-type (Hochholdinger et al. 2008). The mutated gene encodes a GPI-anchored COBRA-like cell wall protein RTH3 that is involved in the organization of the synthesized cellulose (Hochholdinger et al. 2018). The rth3 mutants used in these experiments are genetically highly homozygous because they have been backcrossed to the inbred line B73 for more than 8 generations.

\section{Substrates, sieving and packing}

The loam substrate was obtained from the upper $50 \mathrm{~cm}$ of a haplic Phaeozem soil profile, dried to $10 \%$ gravimetric water content and then sieved down to $<1 \mathrm{~mm}$. The sand substrate constitutes a mix of 83.3\% quartz sand (WF 33, Quarzwerke Weferlingen, Germany) and $16.7 \%$ of the sieved loam. Details on chemical and physical properties are provided in Vetterlein et al. (2021). A brief summary is provided in Table 1.

Columns were packed carefully in order to avoid particle sorting and hence the presence of layers. This was achieved by placing a coarse sieve $(4 \mathrm{~mm}$ of mesh size) above a column during filling which was continuously moved laterally. The loam treatment was packed to a bulk density of $1.26 \mathrm{~g} \mathrm{~cm}^{-3}$, while the sand treatment was packed to a bulk density of $1.47 \mathrm{~g} \mathrm{~cm}^{-3}$ to have comparable bulk densities found in field sites. Filling the columns to the target bulk density was achieved by "tapping" the entire column on a flat surface (Lippold and Ohmann 2019).

\section{Soil column design}

Individual soil columns consist of an acrylic glass tube (25 cm height, $7 \mathrm{~cm}$ inner diameter). A nylon mesh $(30 \mu \mathrm{m}$ mesh size $)$ is placed at the bottom of the column in order to retain the soil. The columns were filled up to $23 \mathrm{~cm}$ height with the substrates (Fig. 1). With such a set-up, the volume available for plant growth is $885 \mathrm{~cm}^{3}$.

\section{Soil fertilisation}

Nitrogen (N), Phosphorus (P), Potassium (K), and Magnesium $(\mathrm{Mg})$ were added at a dose twice as high in sand as compared to loam. Calcium (Ca) as well as micronutrients were only applied to sand (Table 2). This substrate-specific fertilisation was carried out to account for the initial substrate specific differences in nutrient availability. The aim was to achieve a phosphorus level per shoot dry weight which is below adequate supply for the WT genotype $\left(<3.5 \mathrm{mg} \mathrm{g}^{-1}\right.$; (Bergmann 1986)) in order for root hairs to play a role in $\mathrm{P}$ acquisition under $\mathrm{P}$ limiting conditions. 


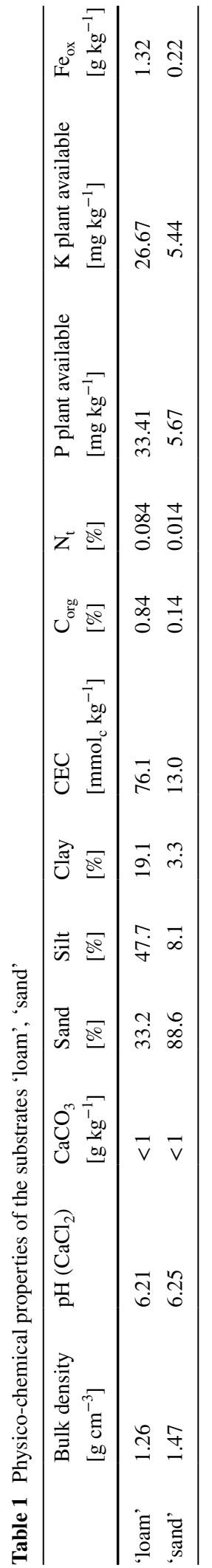

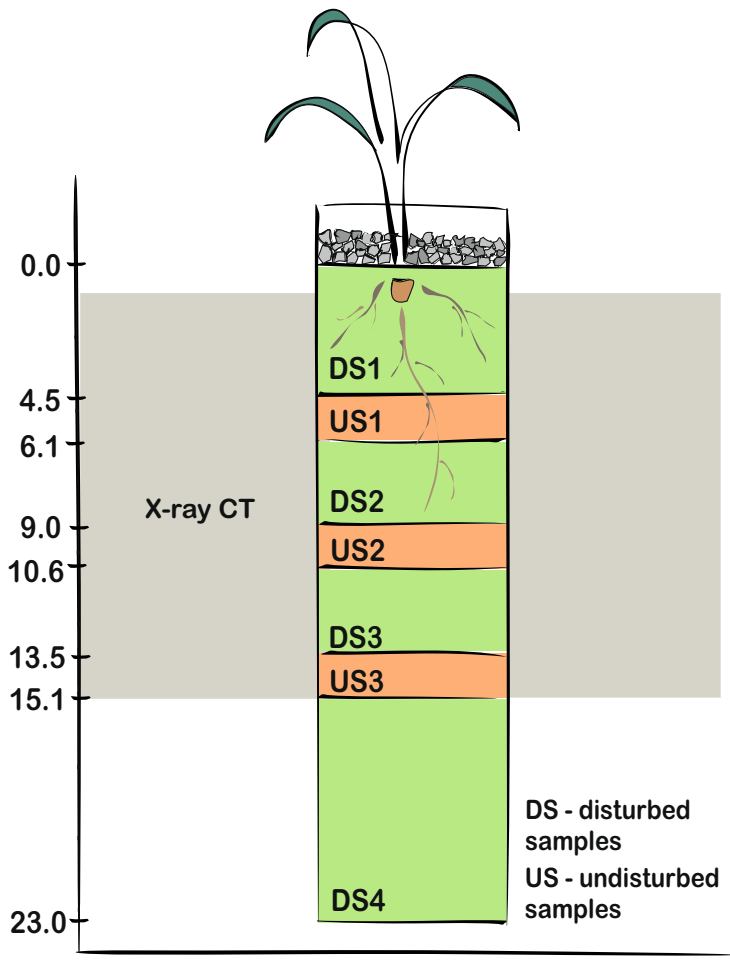

Fig. 1 Sketch of a soil column indicating X-ray CT-scanned depth (grey, 1.0-15.1 cm), depth for destructive sampling (light green, DS1 0-4.5 cm, DS2 6.1-9.0 cm, DS3 10.6$13.5 \mathrm{~cm}$, DS4 $15.1-23.0 \mathrm{~cm}$ ) as well as layers for subsamples providing higher resolution scans and material for microbiome and gene expression analyses addressed in Ganther et al. (2020, 2021) (orange; US1 4.5-6.1 cm, US2 9.0-10.6 cm, US3 $13.5-15.1 \mathrm{~cm})$

The fertilisation dose used in this experiment was tested in pre-trials in order to achieve similar plant growth for WT, but still low plant P status (Vetterlein et al. 2021).

Plant growth conditions

Maize seeds were surface sterilised for 5 min in $10 \%$ hydrogen peroxide and placed at a depth of $1 \mathrm{~cm}$. The soil surface was covered with quartz gravel to reduce evaporation. Columns were carefully watered from top and bottom to an average volumetric water content of $22 \%$ for loam and $18 \%$ for sand. Fluctuation of water content was low as watering intervals were shortened as plant transpiration increased. Growth chamber was set to $22{ }^{\circ} \mathrm{C}$ during the day and $18{ }^{\circ} \mathrm{C}$ at night with a $12 \mathrm{~h}$ light-period, $350 \mu \mathrm{M} \mathrm{m}^{-2} \mathrm{~s}^{-1}$ photosynthetically active radiation and a constant relative 
humidity at $65 \%$. Growth duration was 21 days, i.e. harvest was conducted on day 22 after planting.

Shoot biomass sampling and nutrient analysis

At day 22 after planting, shoots were cut and dried at $65{ }^{\circ} \mathrm{C}$ for $72 \mathrm{~h}$. After the determination of shoot dry weight the material was ground down to fine powder. $\mathrm{C}$ and $\mathrm{N}$ was analysed by combustion with a CNS analyser (vario EL cube, Elementar, Germany). P, K, $\mathrm{Ca}$ were determined by ICP-OES (Inductively coupled plasma- optical emission spectroscopy, ARCOS, Spectro AMETEC, Germany) after pressure digestion with nitric acid and hydrogen peroxide in a microwave (Mars 6, CEM Corporation, USA). Shoot nutrient content was obtained by multiplying the measured tissue concentration and the shoot dry weight. In order to compare the uptake of a nutrient with high mobility to one with low mobility without confounding impact of plant growth, the Ca:P ratio in the shoot biomass was assessed for each replicate.

\section{Destructive sampling of roots and WinRhizo}

After the shoot was cut, the soil was pushed out of the acrylic column using a custom made subsampling device (UGT GmbH, Germany) and then sliced into seven layers. The second, fourth and sixth layer were used for further subsampling (for investigation of spatial gradients, gene expression, microbiome analyses which are presented elsewhere; (Ganther et al. 2020, 2021; Vetterlein et al. 2021). The remaining layers were put on a $0.63 \mu \mathrm{m}$ sieve and roots were washed off carefully with deionised water. Roots were stored in 50\% alcohol solution (i.e. diluted Rotisol ${ }^{\circledR}$ ). Subsequently, roots were scanned at 720 dpi with $35 \mu \mathrm{m}$ resolution using a flatbed scanner (EPSON perfection V700). Root traits were analysed using the software WinRhizo 2019 (Regent Instruments, Canada).

The length of the root hairs was measured under a microscope on one $\mathrm{cm}$ long root segments of lateral roots one $\mathrm{cm}$ after the first emerging hairs above the root tip. Three segments per column were analysed. The mean root hair length was $0.24 \mathrm{~mm}$ with no significant difference between substrates but a tendency towards longer root hairs in sand. 
Mycorrhizal colonization

After scanning with WinRhizo the degree of mycorrhizal colonization was determined. For the depth $6.1-9 \mathrm{~cm}$ (DS2) ten fine root $(\varnothing<1 \mathrm{~mm})$ segments per column were selected for staining with ink (4001 Pelikan ${ }^{\circledR}$ ) after clearing roots in $\mathrm{KOH}(10 \%)$ (Vierheilig et al. 1998). For each column, 100 fields of view were evaluated under the microscope. Following McGonigle et al. (1990), presence of arbuscules, hyphae and vesicles was scored separately.

\section{X-ray CT scanning}

$\mathrm{X}$-ray tomography was performed with an industrial Micro-computed tomograph- $\mu \mathrm{CT}$ (X-TEK XTH 225, Nikon Metrology) operated at $160 \mathrm{kV}$ and $296 \mu \mathrm{A}$. A total of 2748 projections with an exposure time of $500 \mathrm{~ms}$ each were acquired during a full rotation of the columns. Samples were placed $18.2 \mathrm{~cm}$ away from the X-ray source during image acquisition. A $0.5 \mathrm{~mm}$ thick copper filter was used between the source and the column in order to reduce beam artefacts. A lead shield with a window $(2.5 * 2.5 \mathrm{~cm})$ was also placed between source and the column to minimize photons scatter outside the field of view, i.e. to the plant shoot and in the soil outside the field of view. With this setup, the dose per scan measured with a radiophotoluminescence dosimeter in the centre of the column amounts to 1.2 Gy (Lippold et al. 2021). The obtained images were reconstructed into a 3D tomogram having voxel side length of $45 \mu \mathrm{m}$ and an 8-bit greyscale via a filtered back projection algorithm with the CT Pro 3D software (Nikon metrology). During the 8-bit conversion, the greyscale range was normalised with a percentile stretching method which sets the darkest and brightest $0.2 \%$ voxels to 0 and 255 respectively.

X-ray CT scanning was performed at 7, 14 and 21 days after planting (DAP) during night time to not interfere with plant photosynthesis. Columns were scanned at two depth intervals making sure that an overlapping region was present. Each depth interval scan took 23 min to complete. The bottom and top scans were then stitched together so that the analysed region had a vertical extent of -1.27 to $-14.77 \mathrm{~cm}$ from the soil surface (Fig. 1).
Root segmentation

Root segmentation of each column scan was performed with the algorithm Rootine v2 (Phalempin et al. 2021) Rootine v2 is a free macro for the image processing software ImageJ (Schindelin et al. 2012). It combines a series of pre- and postprocessing filters with a shape based detection of cylindrical roots at various scales.

In order to assess the recovery of roots during segmentation, a comparison was made with the results from destructive sampling (DS). The investigated layers were located at the depth of $6.1-9.0 \mathrm{~cm}$ and $10.6-13.5 \mathrm{~cm}$ for DS2 and DS3 respectively (Fig. 1). The obtained root length measurements were compared to the ones obtained with X-ray CT for the soil depths investigated with both methods. The root recovery and the error consistency (i.e. respectively the slope and the coefficient of determination of the line of best fit) were assessed by pooling genotypes and depths together.

X-ray CT derived analysis

The properties of the root systems obtained with X-ray CT data were systematically investigated in a depth-dependent fashion. To perform such analysis, the methods described below were applied sequentially after splitting the full 3D stacks in 20 depth intervals, yielding an equidistant spacing of $6.75 \mathrm{~mm}$ in the $\mathrm{Z}$ direction.

Root length density (RLD): The quantification of RLD was performed after a step of skeletonization with the "Analyse Skeleton" plugin available in the BoneJ plugin suite (Doube et al. 2010). The skeletonization step conducts a medial axis transformation of the segmented root system, thereby reducing every root to a 1 pixel wide object. The RLD was then calculated by dividing the obtained root length by the analysed volume in the considered soil layer. With simple arithmetic operations on the RLD results obtained at different scanning events, the fraction of young roots (i.e. roots younger than 7 days old) was calculated for 14 and 21 DAP.

Mean root diameter: The quantification of the root diameter distribution was performed directly on the segmented root systems with the "Local Thickness" method available in the BoneJ plugin. This method assigns to every root voxel a value corresponding to 
the diameter of the largest sphere that fits into the root and contains it. In order to avoid that big roots contribute to more voxels than smaller roots in the obtained histogram, the results of this method were intersected with the skeletonized images. The resulting images are skeletonized root systems where each medial axis voxel contains the local root diameter information. The histogram of the obtained images is then computed to retrieve the root length corresponding to all diameter classes. Additionally, and in a more condensed fashion, the mean of the frequency distribution (referred here to as the mean root diameter) was assessed by computing the first central moment of the histogram.

Mean root distance: The quantification of the Euclidian distances to root in soil was performed by applying a so-called "Euclidian Distance Transform" on the segmented root systems. This method assigns to every soil voxel a value corresponding to its distance to the closest root in a 3D volume. Retrieving the root distance histogram (RDH) (i.e. the histogram of the results obtained from the Euclidian distance transformation) provides additional information with regard to how roots explore the available soil volume over time (Schlüter et al. 2018). In a similar fashion as for the mean root diameter, the mean of the frequency distribution (referred to as the mean root distance) was assessed by computing the first central moment of the RDH.

Rhizosphere volume fraction $(R V F)$ : The RVF is here defined as the rhizosphere volume divided by the total soil volume analysed. The rhizosphere volume was computed by integrating the RDH over all distances smaller than a given rhizosphere extent. The rhizosphere extent was taken from literature and considered equal for both soil types. The value of $1.8 \mathrm{~mm}$ was deduced from the Fig. 4 in Hendriks et al. (1981) who measured the concentration profile of the isotopically exchangeable soil phosphate at the surface of 5 days old maize root segments grown in a sandy soil. For the WT treatment, the root hair effect on the rhizosphere extent was taken into account by simply adding the measured root hair length of $0.24 \mathrm{~mm}$ to the rhizosphere extent of $1.8 \mathrm{~mm}$.

\section{Statistics}

For all figures, standard errors and mean values of six replicates are provided. A log-transformation was used prior to statistical analyses if normal Q-Q plots and Shapiro test indicated that the normal distribution criterion was not met. The software $\mathrm{R}$ version 3.53 ( $\mathrm{R}$ Core Team 2018) and the libraries lme4, car, multcomp, ggplot and emmeans were used. A two-factorial ANOVA for the fixed factors substrate, genotype and their interaction was conducted in conjunction with Tukey's HSD test. Significant differences between treatments are displayed with small letters for $p<0.05$ in the figures.

\section{Results}

Shoot and root growth, $\mathrm{P}$ acquisition

Plant P tissue concentration was low in both substrates as intended in order for root hairs to play a role in $\mathrm{P}$ acquisition under $\mathrm{P}$ limited conditions (in loam $2.4 \mathrm{mg} \mathrm{g}^{-1}$ for $r$ th 3 and $2.6 \mathrm{mg} \mathrm{g}^{-1}$ for WT, in sand $2.7 \mathrm{mg} \mathrm{g}^{-1}$ for $\mathrm{rth} 3$ and WT). Overall, there was a significant impact of substrate on shoot and root growth, with a shift in root:shoot ratio (Fig. 2a, $b, c)$. Lack of root hairs resulted in a reduction of shoot and root growth. These effects were larger for shoots than for roots, the latter being reflected in a shift in root:shoot ratio towards the roots for rth3 (Fig. 2c). Growth reduction (shoot and root) was larger for loam than for sand and the differences between genotypes were even more obvious for plant $\mathrm{P}$ content (Fig. 2d). There was no significant difference between the genotypes with respect to $\mathrm{P}$ uptake per unit root surface, albeit there was a tendency for lower uptake for $r$ th 3 as compared to WT for loam (Fig. 2e). Likewise the Ca:P ratio showed higher values for $r$ th 3 as compared to WT for loam. However, no difference between genotypes was found for sand (Fig. 2f).

A higher investment in root growth to compensate for the lack of absorbing surface provided by root hairs was not found in absolute terms (Fig. 2b) but in relative terms, at least for loam (Fig. 2c).

The X-ray dose associated with X-ray CT scanning had no significant impact on shoot or root growth with the scan settings and scanning frequency chosen (Fig. S1). 

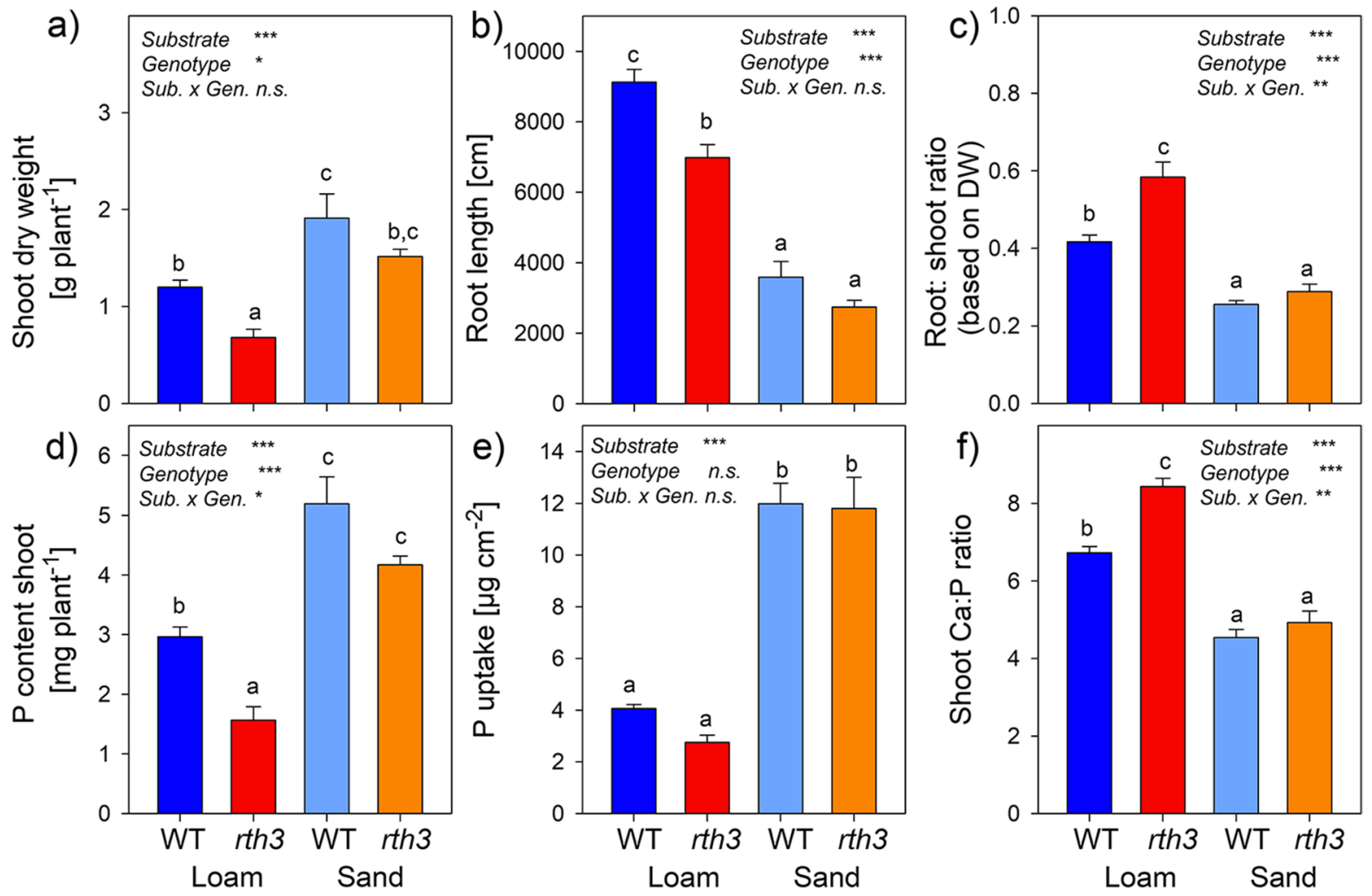

Fig. 2 Impact of substrate (loam, sand) and maize genotype (wild-type-WT, root hair defective mutant rth3-rth3) on shoot dry weight (a), root length (b), root:shoot ratio (c), shoot

\section{Root system architecture in 4D}

Time resolved X-ray CT scanning and superposition of scans from different time points provided insight into the $3 \mathrm{D}$ architecture of the root system and its temporal development including detailed information on root diameters (Fig. 3). Comparison with the sketch of maize root development clearly shows that, with X-ray CT, the primary roots and seminal roots including their laterals can be identified (pink colour-7 days). The roots captured additionally at day 14 (green) mainly represent the crown roots and their laterals, while those captured at day 21 represent the brace roots (blue). It should be noted that this simple assignment between scanning events and root type is only valid for the main root axis and differs in detail for the lateral roots. Note that the recovery of roots with X-ray CT was different for the loam and sand and that this difference should be kept in mind for the interpretation of the X-ray $\mathrm{CT}$ acquired results. The
$\mathrm{P}$ content (d), P uptake per unit root surface (e) and the stoichiometric ratio of the mobile element $\mathrm{Ca}$ over the immobile nutrient $\mathrm{P}(\mathbf{f})$ in the shoot 22 days after planting

recovery of roots was equal to $99 \%\left(R^{2}=0.84 ; n=24\right)$ for the sand treatment whereas it amounted to $71 \%$ $\left(\mathrm{R}^{2}=0.61 ; \mathrm{n}=19\right)$ for the loam treatment (Bulk density $\left.\mathrm{g} \mathrm{cm}^{-3}\right)$.

Root length density (RLD)

Root length density profiles (Fig. 4, Fig. S3) showed significant differences between substrates for most depth intervals at 14 DAP and the lower ones at 21 DAP. Genotype only had a significant impact on depth exploration at 7 DAP, when overall RLD was still very low. For 21 DAP significant impact of genotype in the upper depth intervals is related to desiccation induced artefact described below. Hence, only the differences found for the lower depth intervals will be discussed further. The strong increase in root length density in the lower part of the columns observed for loam towards the end 
Fig. 3 Root system architecture (from - 1.27 to $14.77 \mathrm{~cm}$ depth) derived from X-ray CT scanning at 7,14 and 21 days after planting (pink $=7$ DAP; green $=$ roots grown between 7 and 14 DAP; blue $=$ root grown between 14 and 21 DAP). A representative example for WT (root length of the sample closest to the mean of the six biological replicates per treatment) is shown in both substrates. The sketch in black and grey illustrates the different root types of maize which can be found
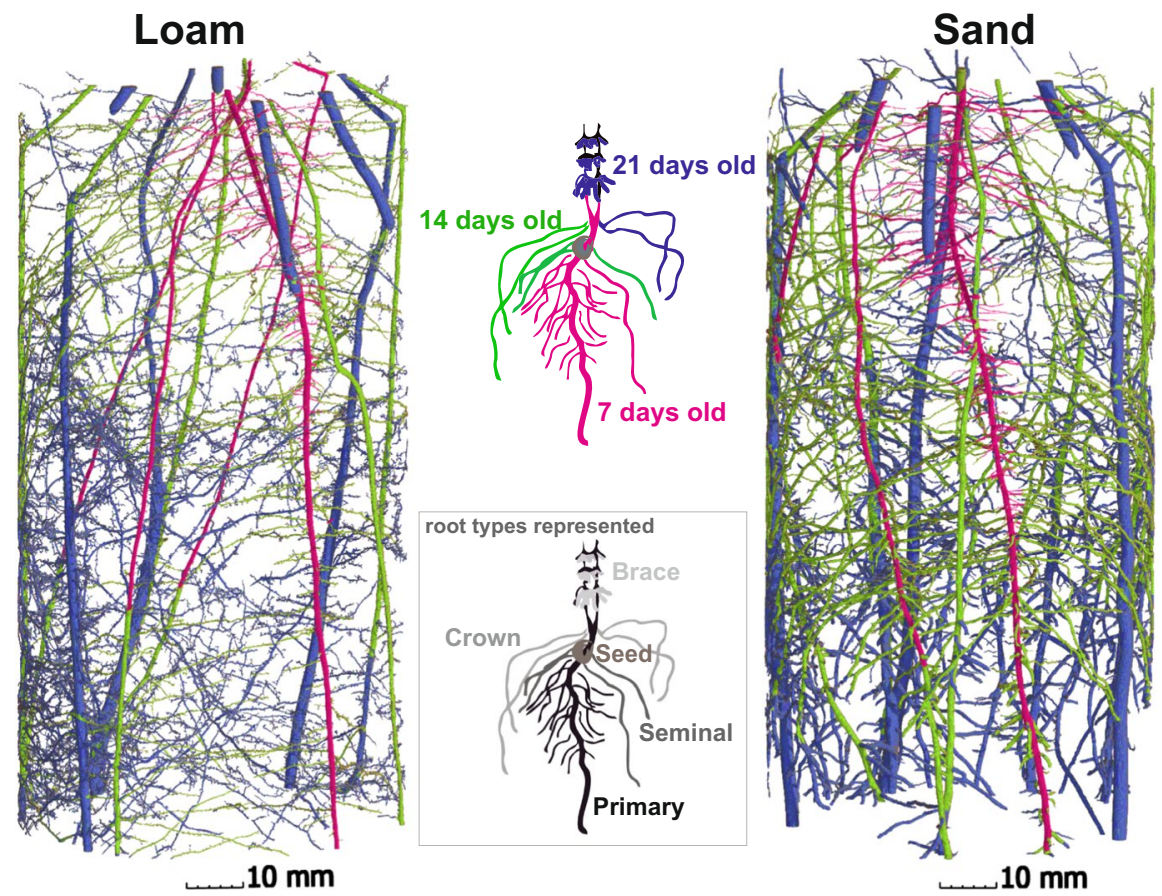

\section{Root length density $\left[\mathrm{cm} . \mathrm{cm}^{-3}\right]$}

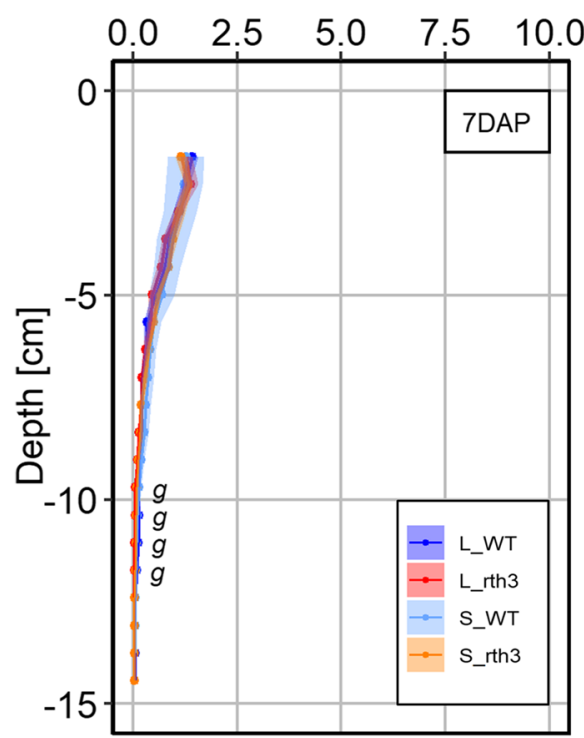

Fig. 4 Change of root length density with depth for 7, 14 and 21 days after planting for two maize genotypes (wild-typeWT, root hair defective mutant $r$ th3-rth3) grown in loam (L) and sand (S). Data are derived from X-ray CT scanning; $n=6$, shaded areas represent standard error. Statistics: two-factorial
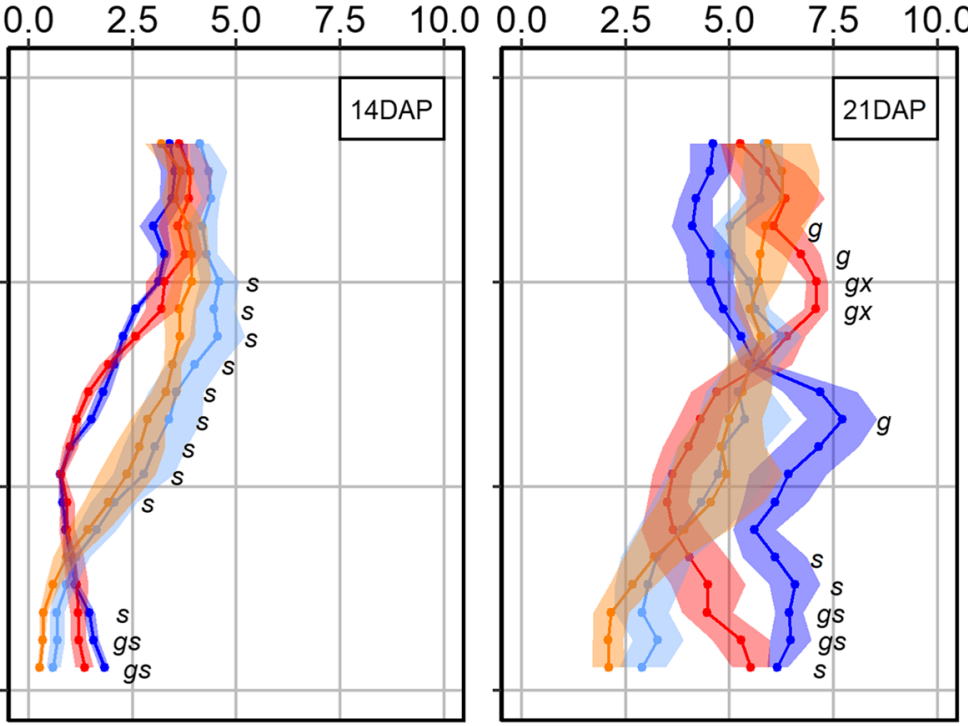

ANOVA in conjunction with Tukey's HSD test was conducted for depth interval. Significant effect of factor is denoted by $s$ for substrate, $g$ for genotype and $x$ for interaction, for $p>0.05$ no letter is displayed 
of the experiment was mostly outside the scanned region. This was quantified by destructive sampling and analysis with WinRhizo at harvest (Fig. S3).

It should be noted that, due to lower recovery of roots in loam than in sand, the root length densities for the loam treatments were underestimated relative to the sand treatments for X-ray CT derived data (Figs. S2, S3). This was especially true for L_WT on day 21 with the highest proportion of roots $<100 \mu \mathrm{m}$ (Fig. S4).

Very likely, a higher root length density at the top of the column for the L_WT treatment at 21 days was not recovered due to the stronger desiccation of the soil, which might have led to root shrinkage. The associated reduction of root diameter could be responsible for a lower recovery of laterals during root segmentation (Fig. 4).

Depth profiles of differences in RLD between two consecutive scans (Fig. 5) show that the share of young roots (i.e. $<7$ days old) in the scanned region is significantly higher for sand than for loam at 14 DAP in most of the lower depth intervals. For loam, plants started to explore deeper unscanned soil layers earlier. At 21 DAP however, this is reversed; i.e. plants in loam showed significantly higher fraction of young roots in the scanned region.
Root diameter distribution: mean root diameter

Root diameter information is available from X-ray CT for all three scanning events (7, 14, 21 DAP) (Fig. 6) and from destructive sampling after harvest (22 DAP) (Fig. S4). The comparison of root diameter distributions in selected depth layers shows a good agreement between the two measuring approaches (data not shown). The root diameter distribution from X-ray CT is summarized with mean root diameter profiles to simplify the comparison between treatments (Fig. 6). Mean root diameter is consistently and for 14 and 21 DAP also significantly smaller for plants grown in loam as compared to those grown in sand, irrespective of soil depth or method used for the analysis of root diameter. For loam, a significantly larger share of roots falls into diameter classes $<200 \mu \mathrm{m}$ (Fig. S4). Differences in root diameter between genotypes are not as obvious; however, for DAP 21 a significant impact of genotype is detected with coarser roots seen for $r$ th 3 especially in sand in X-ray CT based data. For destructive sampling a similar tendency is seen. Mean root diameter based on destructive sampling was $360 \mu \mathrm{m}$ for WT and $390 \mu \mathrm{m}$ for $\mathrm{rth} 3$ in sand, and $230 \mu \mathrm{m}$ for WT and $240 \mu \mathrm{m}$ for $r$ th 3 in loam, respectively.
Fig. 5 Depth distribution of roots younger than 7 days at 14 days and 21 days after planting for two maize genotypes (wild-type-WT, root hair defective mutant rth3-rth3) grown in loam (L) and sand (S). Data are derived by simple arithmetic operations on the dataset shown in Fig. 4; $n=6$, shaded areas represent standard error. Statistics: two-factorial ANOVA in conjunction with Tukey's HSD test was conducted for depth interval. Significant effect of factor is denoted by $s$ for substrate, $g$ for genotype and $x$ for interaction, for $p>0.05$ no letter is displayed

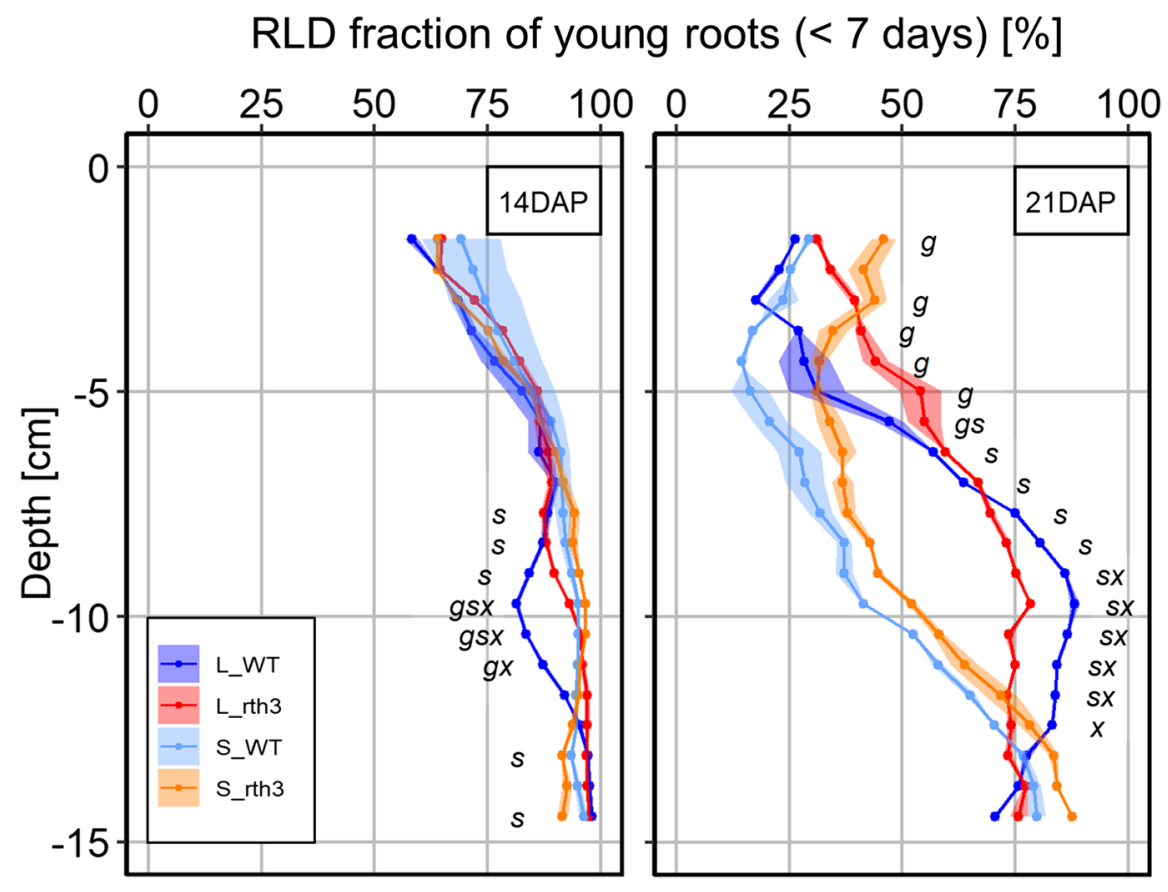




\section{Mean root diameter [mm]}
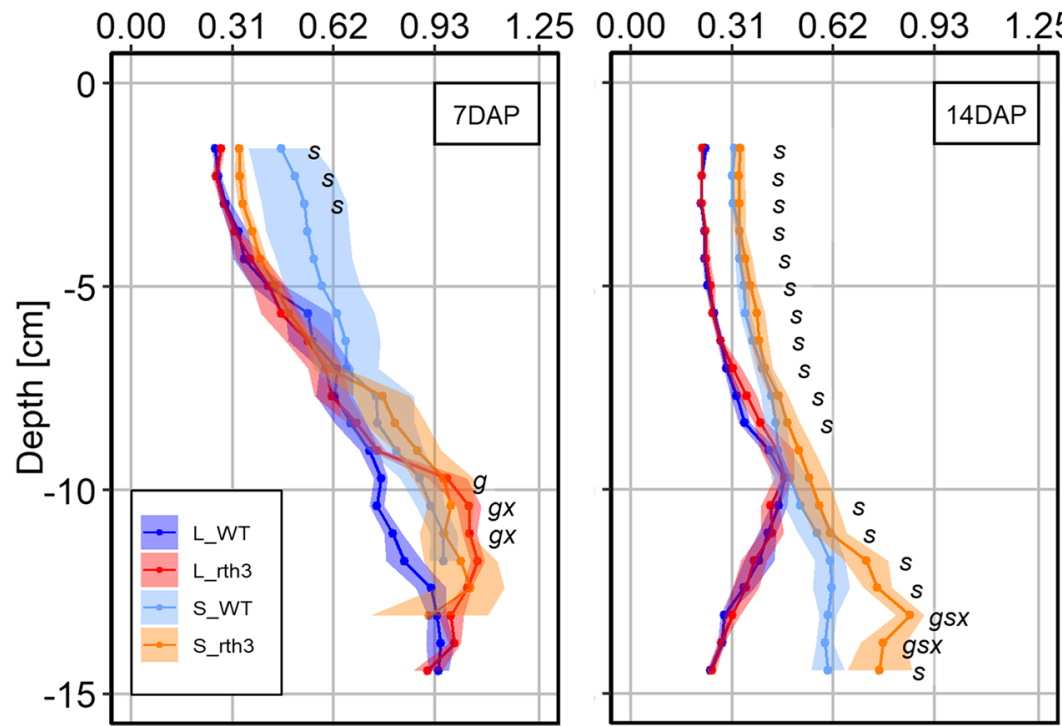

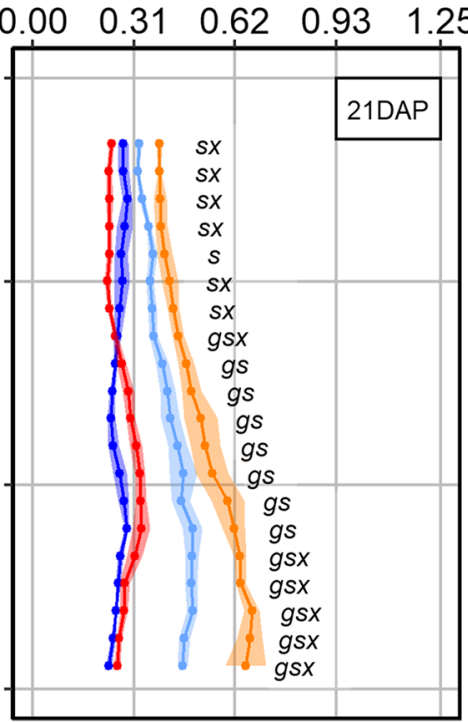

Fig. 6 Change of mean root diameter with depth for 7, 14 and 21 days after planting for two maize genotypes (wild-typeWT, root hair defective mutant $r$ th3-rth3) grown in loam (L) and sand (S). Data are derived from X-ray CT scanning; $n=6$, shaded areas represent standard error. Statistics: two-factorial

\section{Root distance maps}

The exploration of the soil by roots can be visualized with root distance maps (Fig. 7a) and quantified with root distance histograms (RDH) (Fig. 7b). The mean root distance in soil is derived from that $\mathrm{RDH}$ and differentiated according to soil depth (Fig. 8). In general, the mean root distance reflects the root length density rather well (Fig. 4). That is, an increase in root length density results in a higher frequency of short root distances making large distances less frequent (Fig. 7b) and hence reducing mean root distance (Fig. 8). Seven days after planting the root network is poorly developed at the bottom of the field of view and comprises only the primary root and a few seminal roots without laterals, which causes a marked increase of mean root distance with depth. At this early stage the same root length densities in sand and loam evoke different mean root distances across the entire column. This is due to two out of six replicates which had no laterals yet along the primary root at this time point for treatment S_WT (Fig. S5). Their absence has a huge impact on mean root distance in a sparsely populated soil (7 DAP) that is not reflected to the same degree
ANOVA in conjunction with Tukey's HSD test was conducted for depth interval. Significant effect of factor is denoted by $s$ for substrate, $g$ for genotype and $x$ for interaction, for $p>0.05$ no letter is displayed

in RLD. In addition, sand and loam treatments might differ in the spatial arrangement of seminal roots. The seminal roots and the primary root seemed to be more clustered in one semicircle of the column wall in loam as compared to more equidistant radial positions in sand (Fig. S5). At 14 DAP the root length density is higher in sand for almost the entire field of view except for the very bottom (below $-12 \mathrm{~cm}$ ). This difference in RLD was also reflected in the corresponding depth distribution of mean root distance, i.e. shorter mean root distance with a higher RLD and vice versa. At 21 DAP the field of view is already densely populated with roots in both substrates. There seems to be a universal limit at approx. $3 \mathrm{~mm}$ below which the mean root distances cannot fall despite different RLD in the range of $4-8 \mathrm{~cm} \mathrm{~cm}^{-3}$. For all scanning events differences in mean root distance between genotypes are absent in both substrates, except for the lowest depth intervals at 7 DAP.

\section{Rhizosphere volume fractions (RVF)}

We recall that the hypothetical rhizosphere volume fractions (Fig. 9) are directly derived from the root 
Fig. 7 a Root distance maps determined 7,14 and 21 DAP for the S_WT sample depicted in Fig. 3. b The root distance histograms are shifted towards shorter distance with increasing root length density over time
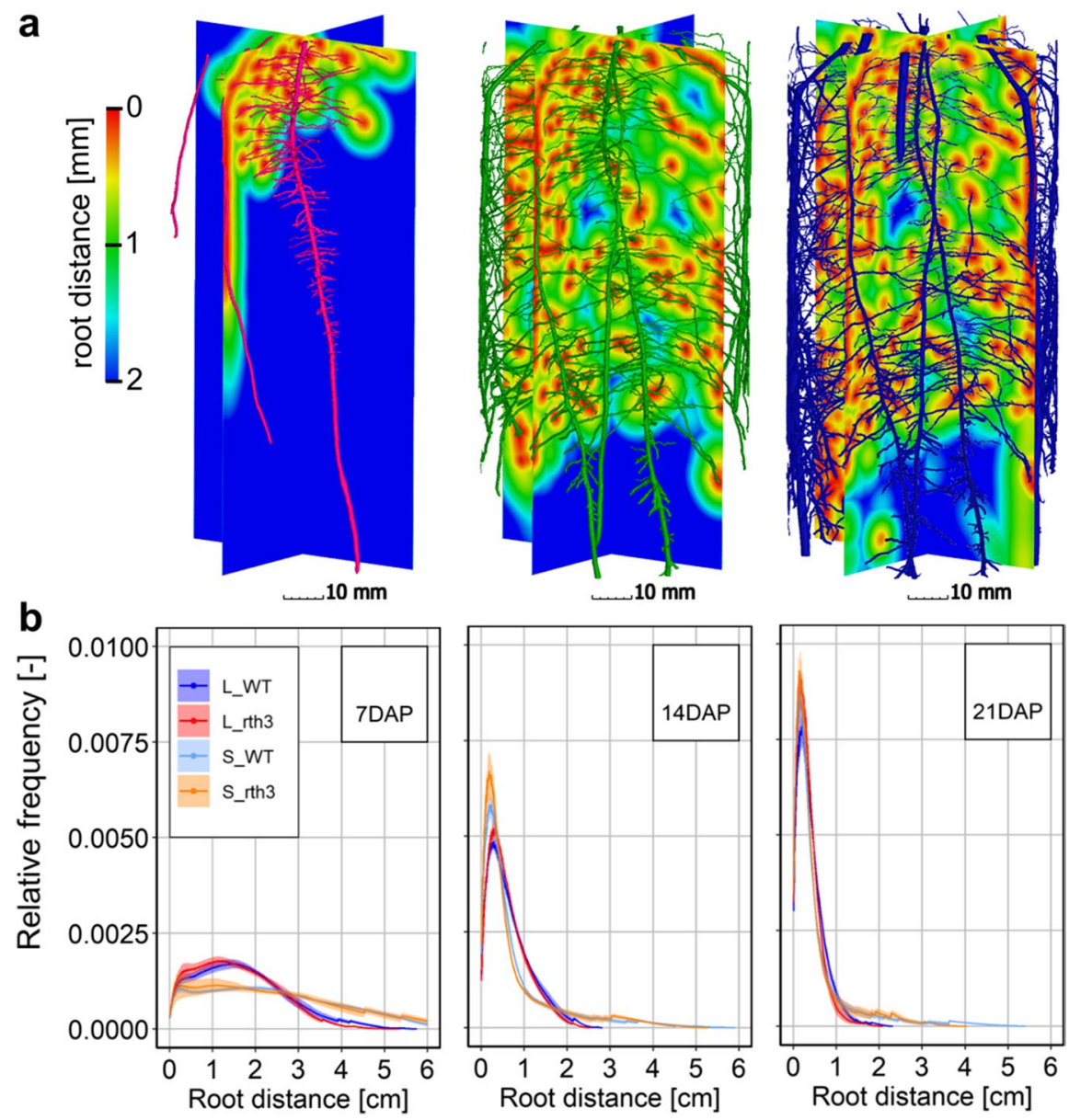

distance histograms by determining the frequency of soil voxels with root distances $<1.8 \mathrm{~mm}$, which we considered to be a typical rhizosphere extent for $\mathrm{P}$. In addition, for root hairs of the maize wild-type, the rhizosphere extent was increased by the measured root hair length of $0.24 \mathrm{~mm}$. Again, the vertical distributions of rhizosphere volume fractions reflect root length density profiles for all time points very well. The only deviation from this congruence is a much higher RVF in the top $5 \mathrm{~cm}$ at 21 DAP in sand despite similar RLD values in that depth. This increase in RVF was not exclusively due to the larger root diameter in sand, as this would have led to more soil voxels in the direct vicinity of the root interface in the entire scanned region and not just the top. The insets at 21 DAP (Fig. 9) show vastly different RVF (orange) for one loam (a) and one sand (b) column with identical RLD. Roots in loam had a preference for growing along the wall, supposedly in cracks that formed due to desiccation. The rhizosphere of roots growing along the wall was truncated to a semi-circle and contributed less to the RVF. Despite explicitly accounting for hair length, genotype had no significant effect on RVF.

\section{Discussion}

For the discussion part of our work, we will attempt to answer our original hypotheses stated in the introduction.

Is the lack of root hairs compensated by an increased investment in root growth in general and more specifically in the growth of fine roots?

Despite employing two complementary root system architecture measurements $(\mu \mathrm{CT}$, destructive sampling), we did not observe an increase in fine 


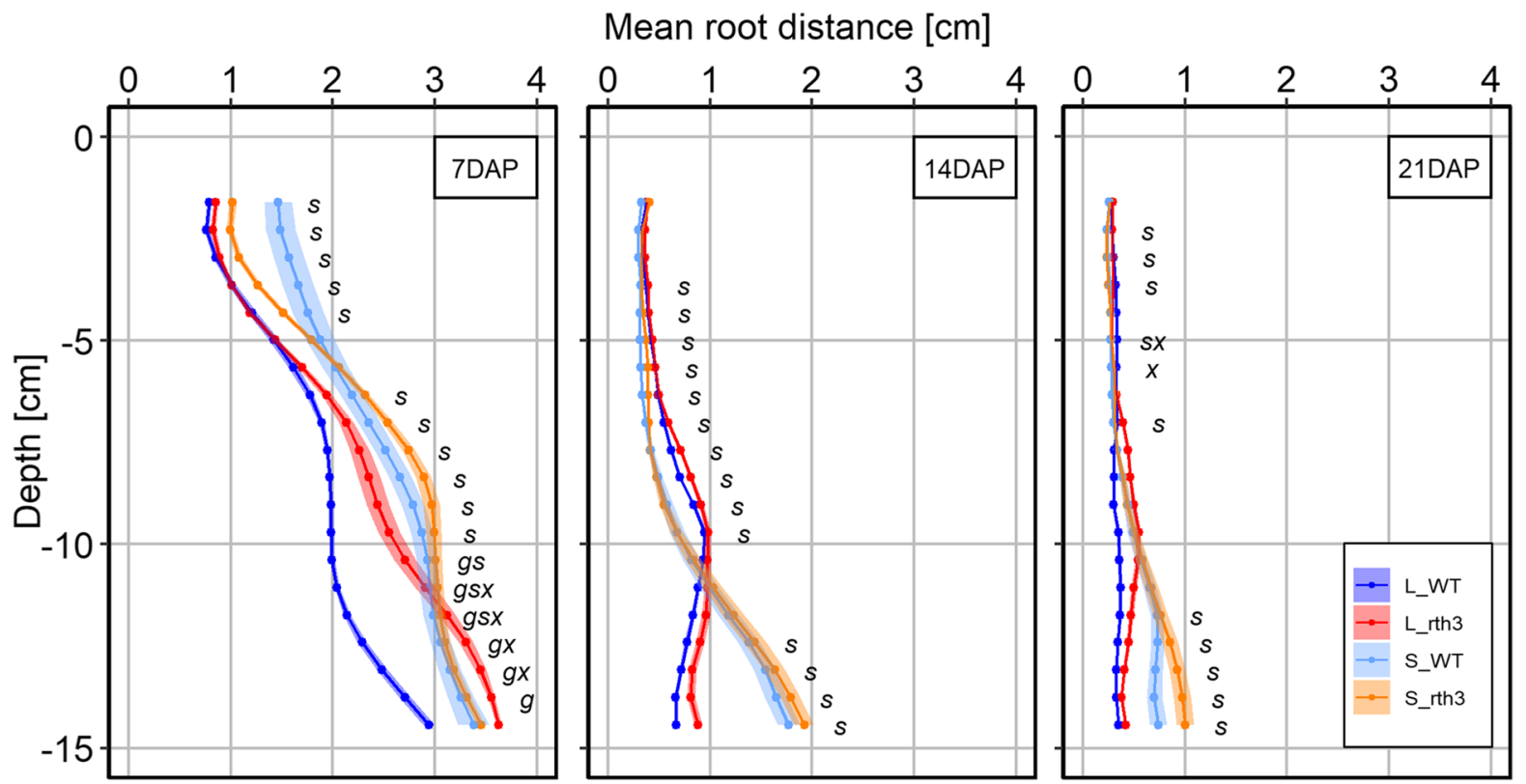

Fig. 8 Depth profile of mean root distance for 7, 14 and 21 days after planting for two maize genotypes (wild-typeWT, root hair defective mutant $r$ th3-rth3) grown in loam (L) and sand (S). Data are derived from frequency distribution of distances derived from distance maps calculated on 3D X-ray

root growth as a compensation for the lack of roots hairs. This is surprising, as the mutant exhibited a plastic response in root growth with respect to substrate. This finding is in contrast to the one by Klamer et al. (2019) who compared Zea mays WT to the root hair defective mutant $r$ th2. They reported a shift towards finer roots for the mutant. However, in order to detect this shift, they had to compile data across treatments differing vastly in $\mathrm{P}$ and water supply. Their plants were growing in subsoil material and were non-mycorrhizal, while the plants in the present experiment showed first signs of mycorrhizal colonization (Table S1) despite the early growth stage. A more intense infection with mycorrhizal fungi as a compensation for the lack of hairs was suggested by Li et al. (2014) for barley and confirmed by Kumar et al. (2019) for maize, but only for later growth stages. The type of mutation is another potential explanation for the differences in compensation mechanism observed by Klamer et al. (2019) and the present experiment. In mutant $r$ th 3 the mutated gene encodes a GPI-anchored COBRA like cell wall protein involved in the organization of the synthesized data; $n=6$, shaded areas represent standard error. Statistics: two-factorial ANOVA in conjunction with Tukey's HSD test was conducted for depth interval. Significant effect of factor is denoted by $s$ for substrate, $g$ for genotype and $x$ for interaction, for $p>0.05$ no letter is displayed

cellulose (Hochholdinger et al. 2008). For the rth2 gene the mechanism is not yet identified.

In general, a significantly higher investment in root growth by the root hair defective mutant as it is reported in literature (Dodd and Diatloff 2016; Klamer et al. 2019) is also found in the present study, although only in relative but not in absolute terms and only for loam, i.e. the substrate with lower P mobility. The shift in root:shoot ratio was not sufficient to compensate for the lack of hairs as total P uptake was significantly lower for $r$ th 3 as compared to WT in loam. With respect to physiological plasticity our results are inconsistent. While without morphological and physiological compensation lower uptake rates per unit root are expected, we found no significant differences in normalized P uptake between the genotypes, with only a tendency towards lower values for $r$ th 3 in the substrate with the lower P mobility. In general, much lower $\mathrm{P}$ uptake rates per unit root surface were found for loam as compared to sand, despite the low plant $\mathrm{P}$ status in loam (leaf tissue $\mathrm{P}$ concentration of $2.4 \mathrm{mg} \mathrm{g}^{-1}$ for $\mathrm{rth} 3$ and $2.6 \mathrm{mg} \mathrm{g}^{-1}$ for WT, which is expected to trigger expression of high affinity $\mathrm{P}$ 
Rhizosphere volume fraction [\%]
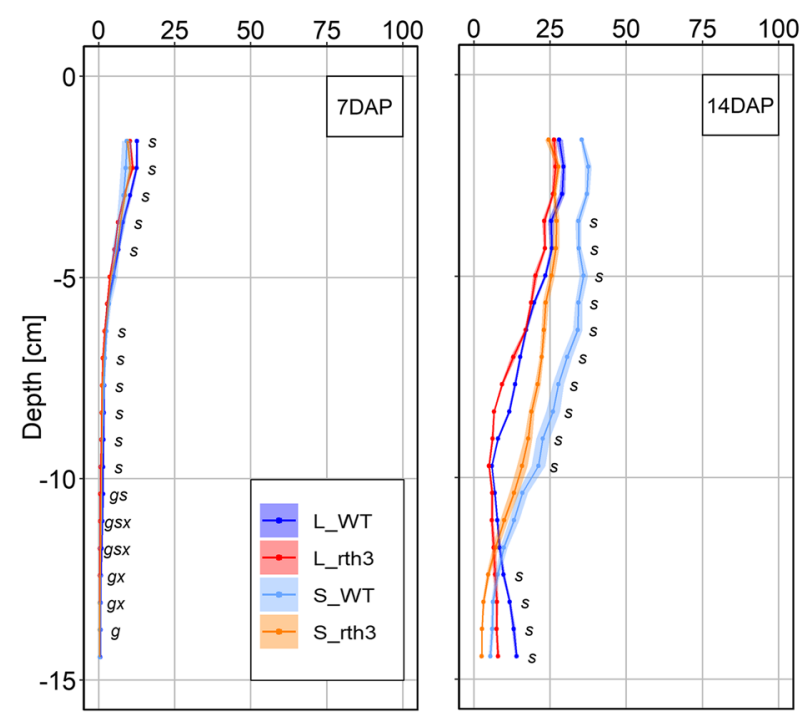

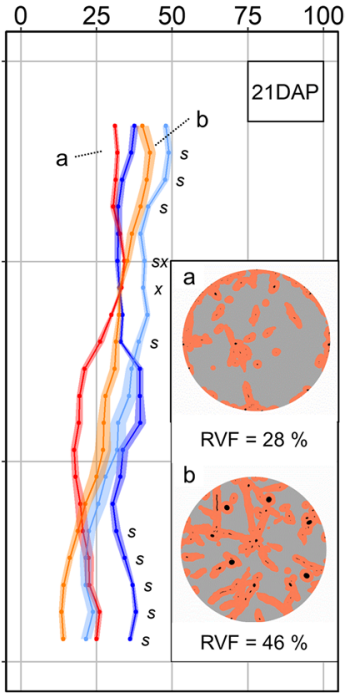

Fig. 9 Depth profile of rhizosphere volume fraction for 7 , 14 and 21 days after planting for two maize genotypes (wildtype-WT, root hair defective mutant rth3-rth3) grown in loam (L) and sand (S). Data are derived from frequency distribution of distances derived from distance maps calculated on 3D X-ray data; Rhizosphere volume fraction is determined assuming a typical rhizosphere extent of $<1.8 \mathrm{~mm}$ for $\mathrm{P}$ deple-

transporters. This is in line with relative root gene expression data for the same experimental setup, reported by Ganther et al. (2021). They did not find gene functions relating to phosphate uptake to be differentially expressed between WT and $r$ th3. It is still possible that the activity of the transporters is regulated at the protein level, since apart from transcriptional regulation, post-translational modifications of phosphate transporters are widespread (Vetterlein and Tarkka 2018). For soil based systems, uptake rate per unit root is strongly influenced by diffusion and root to soil contact. Haling et al. (2013) found significantly lower $\mathrm{P}$ uptake rates per unit root length for the root hair defective mutant of barley compared to the wild-type, for high but more so for low $\mathrm{P}$ soils. Root hairs were relevant for maintaining contact in loose soils and for improved penetration in dense soils. The importance of hairs for $\mathrm{P}$ uptake in particular under conditions of restricted $\mathrm{P}$ transport is confirmed by observations in hydroponics, i.e. systems with no major limitations for transport. Suzuki et al. (2003) found in hydroponic systems no differences in $\mathrm{P}$ uptake rates per unit root dry weight between rice tion reported by Hendriks et al. (1981) for 5 day old root segments. For the wild-type $0.24 \mathrm{~mm}$ were added to account for hair length; $n=6$, shaded areas represent standard error. Statistics: two-factorial ANOVA in conjunction with Tukey's HSD test was conducted for depth interval. Significant effect of factor is denoted by $s$ for substrate, $g$ for genotype and $x$ for interaction, for $p>0.05$ no letter is displayed

genotypes differing in root hair development, irrespective of $\mathrm{P}$ supply. The differences between substrates observed here are related to their differences in $\mathrm{P}$ diffusion.

Is the role of root hairs for anchorage causing an adaptation in root system architecture?: how does this relate to soil exploration?

Bengough et al. (2016) have demonstrated the importance of root hairs for anchorage using the same maize genotypes as in the present study. Peak anchorage forces were up to five times greater for the wild-type compared to the root hair defective mutant. As a consequence, wild-type primary roots penetrated deeper into the soil during a given time interval as compared to the mutant. The difference was fivefold at low bulk density and decreased continuously with increasing bulk density/mechanical impedance. At the bulk density and water content investigated in the present experiment, penetration resistance in both substrates was well below 0.1 MPa (U. Rosskopf, S. Peth, D. Uteau personal communication). This value is an order of magnitude below 
the critical value for root elongation rate of $2 \mathrm{MPa}$ suggested by Bengough et al. (2011). With two exceptions no differences were observed in depth exploration between the two genotypes within the same substrate. At 7 DAP, wild-type showed significantly higher values in the lower depth intervals, which is in line with the postulated role of hairs for anchorage, however in absolute values these differences were very small. A distinct exception occurred for the last time point in loam most likely due to a technical artefact. During the last four days of growth, plant water consumption for wild-type in loam was so high, that short-term desiccation of top soil occurred between the watering events. This likely caused root shrinkage which in turn reduced recovery with X-ray CT. The study of Bengough et al. (2016) focused on the very early growth stage, i.e. 3 days after germination with just the primary root $(1-3 \mathrm{~cm}$ long) at the start of the experiment and a duration of the experiment of maximum $48 \mathrm{~h}$. At later growth stages, it can be expected that lateral root formation as well as seminal roots partly take over the function of anchorage from the hairs (Bailey et al. 2002). Lateral roots on the primary root are abundant at 7 days after planting (Fig. S5).

Root distance histograms were derived from X-ray CT data to quantify soil exploration in more detail, as they simultaneously take into account the actual 3D geometry, differences in length and diameter (Schlüter et al. 2018). Root distance histograms or the mean root distance derived from these data (Figs. 7, 8) are a very sensitive measure in particular at early growth when exploration is poor. This is indicated by the strong impact of delayed lateral root formation in two out of six replicates being reflected in mean root distance but not in RLD (Fig. S5). While the measure nicely reflects the progressive exploration of the soil columns from top to bottom and over time with distinct differences between substrates, no significant differences between genotypes were observed. At later growth stages, when root length densities were higher a limit in mean root distance of $3 \mathrm{~mm}$ was attained. Such a limit in the range of $3 \mathrm{~mm}$ was also reported by Lucas et al. (2019) for root-induced biopores in undisturbed field samples. This suggests that an investment in more root growth may not pay off in terms of better root exploration but only increase competition between roots for the same resources. However, whether that is really the case would be better assessed with nutrient specific rhizosphere volume fractions, which are more sensitive to growth patterns at high RLD.
For the RVF, for which the measured root hair length $(0.24 \mathrm{~mm})$ was explicitly added to the assumed extension of the $\mathrm{P}$ depletion zone $(1.8 \mathrm{~mm}$ derived from Hendriks et al. (1981)) for the wild-type, no significant effect of genotype was detected at 14 and 21 days after planting at all depths. RVF reached 25 to $50 \%$ at day 21 (Fig. 9), indicating that a large fraction was already explored for $\mathrm{P}$ at this early stage. Note that these results are hypothetical and depend on the assumed extension of rhizosphere. More accurate RVF estimates would require spatially resolved information about radial depletion patterns of plant available $\mathrm{P}$ on multiple, intact rhizosphere sections to capture them representatively.

It should be noted that the measured root hair length of $0.24 \mathrm{~mm}$ is rather short as compared to literature data. Frequently higher values in the range of 0.7 to $0.9 \mathrm{~mm}$ are reported for maize (Hendriks et al. 1981; Weber et al. 2018). In general root hair lengths can vary with soil P status and bulk density (Haling et al. 2013; Jungk 2001); there was a tendency towards longer root hairs in sandy substrate. Increasing hair length in our calculation of RVF would result in higher values (Fig. S6). This increase is linear for realistic root lengths. The relative importance of root diameter over root hair length for RVF would increase as the extension assumed for the rhizosphere process in question decreases.

Root length density is the dominant factor that governs differences in RVF. However, genotype (i.e. added hair length) and substrate had an additional impact (Fig. S7). For the latter one cannot disentangle the preferential growth along the wall in loam (fewer neighbouring soil voxels for roots at the wall) from the differences in root diameter (increasing the number of neighbouring soil voxels with circumference) between loam and sand. These results are valid irrespective of the exact value for the hypothetical spatial extent of $\mathrm{P}$ depletion, i.e. for the only variable that could not be measured in our study.

Is the difference between wild-type and mutant larger in a substrate with a high sorption capacity, i.e. low mobility of the limiting nutrients?

Nutrient mobility is expected to be lower in loam as compared to sand as loam has a higher number of sorption sites based on higher content of Fe-oxides, clay and organic matter (Vetterlein et al. 2021). 
Interpretation of biomass nutrient concentration per se is confounded by dilution through growth. Interpretation of shoot nutrient uptake is confounded by differences in shoot size and hence nutrient requirement. To evaluate differences in mobility we therefore used not only $\mathrm{P}$ uptake itself, but in addition the stoichiometric ratio of $\mathrm{Ca}$ (having a high mobility in soils) over P (having a low mobility in soils) (Aggren and Weih 2012). For our substrates Ca:P ratio was well suited to show the differences between genotypes for loam. Differences between genotypes were significant for most of the measured growth and uptake parameters in loam, but not in sand. This is in line with our hypothesis and the observation of others (Haling et al. 2013; Suzuki et al. 2003), i.e. roots hairs only matter if transport to the root surface is limiting uptake.

Why do we see a high plasticity with respect to substrate, but only small compensation for the lack of root hairs?

While differences between genotypes in root traits were small in loam or absent in sand for most time points and soil depths, they were very prominent between substrates, irrespective of genotype. This is all the more remarkable as X-ray CT measurements systematically underestimated the root length (in particular fine roots) in loam. Differences between substrates were observed for root diameter, for depth distribution of RLD, share of young roots and the associated measurements such as mean root distance and RVF. While some literature suggests that intensive fine root development can increase $\mathrm{P}$ uptake (Lynch 2011; Richardson et al. 2009), this is only true if $\mathrm{P}$ is non-uniformly distributed, e.g. greater in topsoil as found in most soils. In uniform low $\mathrm{P}$, it is more common that exploratory behaviour is favoured, with increased branching only occurring when a patch of greater $\mathrm{P}$ is encountered As reviewed by Mollier and Pellerin (1999), a shift in root:shoot ratio is found in most studies, but results regarding root length or more specific root traits are inconsistent. In their own study with maize, they observed only a transient promotion of root growth 4 days after $\mathrm{P}$ starvation, which was related to carbon partitioning between shoot and root. Despite these findings, there is an agreement that local increase in $\mathrm{P}$ supply promotes lateral root formation in a P deficient system (Gao et al. 2019).
In the current experiment, we rule out $\mathrm{P}$ supply as a reason for shift in root traits between substrates. Indeed, P supply was homogenous and no differences between genotypes in loam were detected, despite their difference in $\mathrm{P}$ uptake.

Roots in loam showed a shift to smaller root diameter classes (Fig. S4) and smaller mean root diameters across all depth intervals and both genotypes (Fig. 6). Differences in root diameters were detected early on and were very consistent at later time points. Changes were observed in all diameter classes. Careful inspection of segmented images (Fig. 3) indicated that all root types were affected, i.e. it was not only due to a shift in the share of main axis (primary, seminal, crown, and brace roots) and lateral roots. It should be noted, that for 21 DAP an additional differentiation in root diameter between genotypes was observed. Especially in sand coarser roots were detected for $r$ th 3 compared to the wild-type.

The most frequent cause for shifts in root diameter reported in literature is alterations in soil compaction, bulk density and mechanical impedance, which are tightly linked with changes in soil water content and gas diffusion (Bengough et al. 2006, 2011; Clark et al. 2003; Colombi and Walter 2016; Correa et al. 2019). Root diameter increase by up to twofold in case of mechanical impedance has been reported, as a result of cortical cells expanding radially due to microfibril reorientation in the primary cell wall (Bengough et al. 2011). Causal relationship is straight forward, if increasing bulk densities within the same soil/substrate are investigated (Haling et al. 2013; Tracy et al. 2012). An increase in root diameter upon compaction was also observed for our loam in a parallel experiment (Table S2). When comparing different substrates causal relationships are more difficult to unravel. Kirby and Bengough (2002) have nicely shown for the comparison of a sandy loam and a clay loam that penetration resistance alone is not sufficient to predict root thickening. They demonstrated that local values of axial and shear stresses experienced by the root near its tip may be as important as penetration resistance in constraining root growth. Ethylene is often associated with the morphological response of roots to mechanical impedance (Clark et al. 2003; Dreyer and Edelmann 2018). Increased levels of ethylene have been observed to induce increase in root diameter even for unimpeded roots (Baluška et al. 1993). An induced expression of genes related to phytohormone signalling was detected only in sand by Ganther 
et al. (2021) in an experimental setup like the one used here. Ethylene, but also gibberellic acid and jasmonate were affected, which indicates that processes related to development and growth are altered by the substrate. Further studies are required to evaluate whether observed differences can be explained by mechanical properties beyond mechanical impedance (Kirby and Bengough 2002), root (Ma et al. 2013; Pandey et al. 2021) or microbiome ethylene production (Zhang et al. 2020) or differences in diffusion processes within the root or in the rhizosphere (Hartman 2020). Anoxia as a trigger for ethylene production is ruled out for our system, at least not beyond occasional microsites. At the volumetric water content used in this experiment ( $22 \%$ in loam, $18 \%$ in sand), air filled pore volume is well above $10 \%$ even at the bottom of the sand columns (Vetterlein et al. 2021).

Increase in root diameter in sand as compared to loam did not result in an increased investment in root growth in general. Root:shoot ratio was lower in sand. This suggests that plant demands in terms of water and nutrients could be covered with a less intensive soil exploration. As differences in $\mathrm{P}$ uptake did not occur in sand it is difficult to assess whether compensation for the lack of root hairs did not occur in sand because there was no need for it or because fine root growth was hindered by other factors in this substrate. Unfortunately, no support for either possibility can be derived from the data of Klamer et al. (2019) as they have evaluated changes in diameter across all treatments including two textures.

System limitations - relevance for field conditions

It should be noted that despite major advances in root segmentation in the past years (Phalempin et al. 2021; Soltaninejad et al. 2020), we still face the trade-off between image resolution and sample size resulting in fine roots being partly missed out. In the present case, this afflicts the differences between sand and loam as the share of fine roots was larger in loam. Smaller column diameters associated with a higher scanning resolution would have overcome this problem, but would have restricted our experiment to even shorter growth period. One could argue that already in the present setup results after 14 days are less confounded by the limited volume than the ones obtained 21 days after planting. This is also reflected in the higher standard errors observed for the later time point. Shorter growth durations would make it even more difficult to account for interaction of roots with the microbiome, in particular the mycorrhizal symbiosis, which is only starting to interact within the given time (Vetterlein and Tarkka 2018). Moreover, we emphasize the limitation of pot trials for the study of exploration strategies. The limited soil volume of pot trials may induce feedback loops which would not be observed in the field at the same time point. Comparison of present data with those from the field with the same treatments (Vetterlein et al. 2021) will not only show whether the findings are consistent but in particular how much we can learn under controlled conditions about the behaviour in the field.

\section{Conclusion}

Adaptations in root system architecture in response to lacking root hairs were investigated with a comprehensive experimental setup that combined nutrient uptake analysis, destructive root sampling and X-ray CT scanning that allows monitoring various root system architecture metrics over time. The CT derived metrics enable quantification of soil exploration and at the same time integrate the effect of various root traits, i.e. root diameter, 3D-distribution, depth distribution, hair length.

Experimental conditions were well suited to confirm the general consensus on root hairs being of particular relevance for uptake of low mobility nutrients such as $\mathrm{P}$, especially in soils with a high sorption capacity. Root hair defective mutants showed low plasticity of root traits related to limited $\mathrm{P}$ availability, despite their general ability to express high root plasticity. The function of the root hairs for anchoring did not result in different depth profiles of the root length density. We suggest that, in more developed root systems, as in our experiment, part of the anchoring function can be taken over by lateral roots.

Both maize genotypes showed a marked response to substrates differing in soil texture mainly reflected in mean root diameter. Increase in root diameter is typically induced by higher penetration resistance. However, penetration resistance was low at the given water content in both substrates. Further experiments are required to elucidate whether observed differences can be explained by mechanical properties beyond mechanical impedance, root or microbiome ethylene production or differences in diffusion processes 
within the root or in the rhizosphere. A more systematic literature review including studies comparing textures at different levels of nutrient supply is needed. Results from field studies comparing different substrates under the same environmental conditions can also help to unravel the mechanisms involved.

Acknowledgements This project was carried out in the framework of the priority programme 2089

"Rhizosphere spatiotemporal organisation-a key to rhizosphere functions" funded by DFG, German Research Foundation (project number 403801423). Seeds of the maize wild-type and mutant $r$ th 3 were provided by Caroline Marcon and Frank Hochholdinger (University of Bonn). We thank Toni Fahrenkampf for compiling Fig. S5. Jointly with Franziska Busch he supported the experimental work. Isabell Metzen and Marcel Bucher shared their mycorrhizal staining and scoring protocol for maize roots with us. Mika Tarkka, Nina Naderi, and AnneSophie Wachter contributed to analysing the roots for mycorrhizal colonization. Maik Lucas helped with the realisation of the additional experiment with different bulk densities. Bernd Apelt supported all laboratory work and Sebastian Blaser shared his experience with column experiments. CT work was supported by Maximilian John Köhne. ICP-OES measurements were conducted by Ines Volkmann. We thank Stephan Peth, Ulla Rosskopf and Daniel Uteau for sharing the unpublished information on penetration resistance of loam and sand with us.

Authors' contribution All authors contributed to the study conception and design. Material preparation, data collection and analysis were performed by EL and MP. The first draft of the manuscript was written by EL, MP, SS, and DV. All authors commented on previous versions of the manuscript. All authors read and approved the final manuscript.

Funding Open Access funding enabled and organized by Projekt DEAL. This project was funded by DFG, German Research Foundation (project number 403801423, 403640293) as part of priority programme 2089 "Rhizosphere spatiotemporal organisation-a key to rhizosphere functions".

Data availability The datasets generated during and/or analysed during the current study are available from the corresponding author on reasonable request.

\section{Declarations}

Conflict of interest The authors have no relevant financial or non-financial interests to disclose.

Open Access This article is licensed under a Creative Commons Attribution 4.0 International License, which permits use, sharing, adaptation, distribution and reproduction in any medium or format, as long as you give appropriate credit to the original author(s) and the source, provide a link to the Creative Commons licence, and indicate if changes were made. The images or other third party material in this article are included in the article's Creative Commons licence, unless indicated otherwise in a credit line to the material. If material is not included in the article's Creative Commons licence and your intended use is not permitted by statutory regulation or exceeds the permitted use, you will need to obtain permission directly from the copyright holder. To view a copy of this licence, visit http://creativecommons.org/licenses/by/4.0/.

\section{References}

Ågren GI, Weih M (2012) Plant stoichiometry at different scales: element concentration patterns reflect environment more than genotype. New Phytol 194:944-952

Bailey PH, Currey J, Fitter A (2002) The role of root system architecture and root hairs in promoting anchorage against uprooting forces in Allium cepa and root mutants of Arabidopsis thaliana. J Exp Bot 53:333-340

Baluška F, Brailsford R, Hauskrecht M, Jackson M, Barlow P (1993) Cellular dimorphism in the maize root cortex: involvement of microtubules, ethylene and gibberellin in the differentiation of cellular behaviour in postmitotic growth zones. Bot Acta 106:394-403

Bates TR, Lynch JP (2001) Root hairs confer a competitive advantage under low phosphorus availability. Plant Soil 236:243-250

Bengough AG, Bransby MF, Hans J, McKenna SJ, Roberts TJ, Valentine TA (2006) Root responses to soil physical conditions; growth dynamics from field to cell. J Exp Bot 57:437-447

Bengough AG, McKenzie B, Hallett P, Valentine T (2011) Root elongation, water stress, and mechanical impedance: a review of limiting stresses and beneficial root tip traits. J Exp Bot 62:59-68

Bengough AG, Loades K, McKenzie BM (2016) Root hairs aid soil penetration by anchoring the root surface to pore walls. J Exp Bot 67:1071-1078

Bergmann W 1986 Farbatlas Ernährungsstörungen bei Kulturpflanzen: Visuelle und analytische Diagnose. Fischer Verlag, Jena. 306 p.

Carminati A, Passioura JB, Zarebanadkouki M, Ahmed MA, Ryan PR, Watt M, Delhaize E (2017) Root hairs enable high transpiration rates in drying soils. New Phytol 216:771-781

Clark LJ, Whalley WR, Barraclough PB (2003) How do roots penetrate strong soil? Plant Soil 255:93-104

Colombi T, Walter A (2016) Root responses of triticale and soybean to soil compaction in the field are reproducible under controlled conditions. Funct Plant Biol 43:114-128

Correa J, Postma JA, Watt M, Wojciechowski T (2019) Soil compaction and the architectural plasticity of root systems. J Exp Bot 70:6019-6034

Dodd IC, Diatloff E (2016) Enhanced root growth of the brb (bald root barley) mutant in drying soil allows similar shoot physiological responses to soil water deficit as wild-type plants. Funct Plant Biol 43:199-206

Doube M, KlLosowski MLM, Arganda-Carreras I, Cordeli\'eres FP, Dougherty RP, Jackson JS, Schmid B, Hutchinson JR, Shefelbine SJ (2010) BoneJ: free and extensible bone image analysis in ImageJ. Bone 47:1076-1079 
Dreyer J, Edelmann HG (2018) Root cap-mediated evaluation of soil resistance towards graviresponding roots of maize (Zea mays L.) and the relevance of ethylene. Ann Bot 122:791-800

Ganther M, Yim B, Ibrahim Z, Bienert MD, Lippold E, Maccario L, Sørensen SJ, Bienert GP, Vetterlein D, HeintzBuschart A (2020) Compatibility of X-ray computed tomography with plant gene expression profiling, rhizosphere bacterial community composition and enzyme activity analyses. J Exp Bot 71:5603-5614

Ganther M, Vetterlein D, Heintz-Buschart A, Tarkka MT (2021) Transcriptome sequencing analysis of maize roots reveals the effects of substrate and root hair formation in a spatial context. Plant Soil. https://doi.org/10. 1007/s11104-021-04921-0

Gao W, Blaser SR, Schlüter S, Shen J, Vetterlein D (2019) Effect of localised phosphorus application on root growth and soil nutrient dynamics in situ-comparison of maize (Zea mays) and faba bean (Vicia faba) at the seedling stage. Plant Soil 441:469-483

Haling RE, Brown LK, Bengough AG, Young IM, Hallett PD, White PJ, George TS (2013) Root hairs improve root penetration, root-soil contact, and phosphorus acquisition in soils of different strength. J Exp Bot 64:3711-3721

Hartman S (2020) Trapped in the rhizosheath: root-bacterial interactions modulate ethylene signaling. Plant Physiol 183:443

Hendriks L, Claassen N, Jungk A (1981) Phosphatverarmung des wurzelnahen bodens und phosphataufnahme von mais und raps. Z Pflanzenernähr Bodenkd 144:486-499

Hochholdinger F, Wen TJ, Zimmermann R, Chimot-Marolle P, Da Costae Silva O, Bruce W, Lamkey KR, Wienand U, Schnable PS (2008) The maize (Zea mays L.) roothairless3 gene encodes a putative GPI-anchored, monocot-specific, COBRA-like protein that significantly affects grain yield. Plant J 54:888-898

Hochholdinger F, Yu P, Marcon C (2018) Genetic control of root system development in maize. Trends Plant Sci 23:79-88

Hodge A (2006) Plastic plants and patchy soils. J Exp Bot 57:401-411

Hodge A (2009) Root decisions. Plant Cell Environ 32:628-640

Hoffmann C, Jungk A (1995) Growth and phosphorus supply of sugar beet as affected by soil compaction and water tension. Plant Soil 176:15-25

Jungk A (2001) Root hairs and the acquisition of plant nutrients from soil. J Plant Nutr Soil Sci 164:121-129

Kirby J, Bengough A (2002) Influence of soil strength on root growth: experiments and analysis using a criticalstate model. Eur J Soil Sci 53:119-127

Klamer F, Vogel F, Li X, Bremer H, Neumann G, Neuhäuser B, Hochholdinger F, Ludewig U (2019) Estimating the importance of maize root hairs in low phosphorus conditions and under drought. Ann Bot 124:961-968

Kumar A, Shahbaz M, Koirala M, Blagodatskaya E, Seidel SJ, Kuzyakov Y, Pausch J (2019) Root trait plasticity and plant nutrient acquisition in phosphorus limited soil. J Plant Nutr Soil Sci 182:945-952
Li T, Lin G, Zhang X, Chen Y, Zhang S, Chen B (2014) Relative importance of an arbuscular mycorrhizal fungus (Rhizophagus intraradices) and root hairs in plant drought tolerance. Mycorrhiza 24:595-602

Lippold E, Kleinau P, Blaser SRGA, Schlüter S, Phalempin $M$, Vetterlein D (2021) In soil measurement of radiation dose caused by X-ray computed tomography. J Plant Nutr Soil Sci. https://doi.org/10.1002/jpln.202000276

Lippold E, Luise O, (2019) Video filling soil columns. Available via. https://www.ufz.de/export/data/458/239143_filli ng_columns.mp4 Accessed 14 Dec 2020

Lucas M, Schlüter S, Vogel H-J, Vetterlein D (2019) Roots compact the surrounding soil depending on the structures they encounter. Sci Rep 9:1-13

Lynch JP (2011) Root phenes for enhanced soil exploration and phosphorus acquisition: tools for future crops. Plant Physiol 156:1041-1049

Lynch JP, Ho MD (2005) Rhizoeconomics: carbon costs of phosphorus acquisition. Plant Soil 269:45-56

Ma B, He S-J, Duan K-X, Yin C-C, Chen H, Yang C, Xiong Q, Song Q-X, Lu X, Chen H-W (2013) Identification of rice ethylene-response mutants and characterization of MHZ7/ OsEIN2 in distinct ethylene response and yield trait regulation. Mol Plant 6:1830-1848

Marin M, Feeney DS, Brown LK, Naveed M, Ruiz S, Koebernick N, Bengough AG, Hallett PD, Roose T, Puertolas J, Dodd IC, George TS (2020) Significance of root hairs for plant performance under contrasting field conditions and water deficit. Ann Bot. https://doi.org/10.1093/aob/mcaa1 81

McGonigle T, Miller M, Evans D, Fairchild G, Swan J (1990) A new method which gives an objective measure of colonization of roots by vesicular-arbuscular mycorrhizal fungi. New Phytol 115:495-501

Mollier A, Pellerin S (1999) Maize root system growth and development as influenced by phosphorus deficiency. J Exp Bot 50:487-497

Morris EC, Griffiths M, Golebiowska A, Mairhofer S, BurrHersey J, Goh T, Von Wangenheim D, Atkinson B, Sturrock CJ, Lynch JP (2017) Shaping 3D root system architecture. Curr Biol 27:R919-R930

Pandey BK, Huang G, Bhosale R, Hartman S, Sturrock CJ, Jose L, Martin OC, Karady M, Voesenek LACJ, LjungK LJP, Brown KM, Whalley WR, Mooney SJ, Zhang D, Bennett MJ (2021) Plant roots sense soil compaction through restricted ethylene diffusion. Science 371:276-280

Phalempin M, Lippold E, Vetterlein D, Schlüter S (2021) An improved method for the segmentation of roots from X-Ray computed tomography 3D images: Rootine v. 2. Plant Methods 17:39

Pierret A, Doussan C, Capowiez Y, Bastardie F (2007) Root functional architecture: a framework for modeling the interplay between roots and soil. Vadose Zone J. 6:269-281

R Core Team (2018) R: a language and environment for statistical computing. R foundation for statistical computing, Vienna, Austria. Available online at https://www.R-proje ct.org/

Richardson AE, Hocking PJ, Simpson RJ, George TS (2009) Plant mechanisms to optimise access to soil phosphorus. Crop Pasture Sci 60:124-143 
Schindelin J, Arganda-Carreras I, Frise E, Kaynig V, Longair M, Pietzsch T, Preibisch S, Rueden C, Saalfeld S, Schmid B (2012) Fiji: an open-source platform for biologicalimage analysis. Nat Methods 9:676-682

Schlüter S, Blaser SR, Weber M, Schmidt V, Vetterlein D (2018) Quantification of root growth patterns from the soil perspective via root distance models. Front Plant Sci 9:1084

Schmidt JE, Gaudin AC (2017) Toward an integrated root ideotype for irrigated systems. Trends Plant Sci 22:433-443

Soltaninejad M, Sturrock CJ, Griffiths M, Pridmore TP, Pound MP (2020) Three dimensional root CT segmentation using multi-resolution encoder-decoder networks. IEEE Trans Image Process 29:6667-6679

Suzuki N, Taketa S, Ichii M (2003) Morphological and physiological characteristics of a root-hairless mutant in rice (Oryza sativa L.). Plant Soil 255:9-17

Tracy SR, Black CR, Roberts JA, McNeill A, Davidson R, Tester M, Samec M, Korošak D, Sturrock C, Mooney SJ (2012) Quantifying the effect of soil compaction on three varieties of wheat (Triticum aestivum L.) using X-ray micro computed tomography (CT). Plant Soil 353:195-208

Vetterlein D, Doussan C (2016) Root age distribution: how does it matter in plant processes? a focus on water uptake. Plant Soil 407:145-160

Vetterlein D, Tarkka M (2018) Seeds with low phosphorus content: not so bad after all? J Exp Bot 69:4993-4996

Vetterlein D, Lippold E, Schreiter S, Phalempin M, Fahrenkampf T, Hochholdinger F, Marcon C, Tarkka M, Oburger E, Ahmed M, Javaux M, Schlüter S (2021) Experimental platforms for the investigation of spatiotemporal patterns in the rhizosphere - laboratory and field scale. J Plant Nutr Soil Sci. https://doi.org/10.1002/jpln.202000079

Vierheilig H, Coughlan AP, Wyss U, Piché Y (1998) Ink and vinegar, a simple staining technique for arbuscular-mycorrhizal fungi. Appl Environ Microbiol 64:5004-5007

Wang Y, Lambers H (2020) Root-released organic anions in response to low phosphorus availability: recent progress, challenges and future perspectives. Plant Soil 447:135-156

Weber N, Herrmann I, Hochholdinger F, Ludewig U, Neumann G (2018) PGPR-induced growth stimulation and nutrient acquisition in maize: do root hairs matter? Sci Agric Bohem 49:164-172

Wen TJ, Schnable PS (1994) Analyses of mutants of three genes that influence root hair development in Zea mays (Gramineae) suggest that root hairs are dispensable. Am J Bot 81:833-842

Wen Z, Li H, Shen Q, Tang X, Xiong C, Li H, Pang J, Ryan MH, Lambers H, Shen J (2019) Tradeoffs among root morphology, exudation and mycorrhizal symbioses for phosphorus-acquisition strategies of 16 crop species. New Phytol 223:882-895

Zhang Y, Du H, Xu F, Ding Y, Gui Y, Zhang J, Xu W (2020) Root-bacteria associations $\mathrm{b}$ oost rhizosheath formation in moderately dry soil through ethylene responses. Plant Physiol 183:780-792

Publisher's note Springer Nature remains neutral with regard to jurisdictional claims in published maps and institutional affiliations. 